\title{
Complementary Feeding
}

Nutrition\& Metabolism

\section{Complementary Feeding in Developed Countries: The 3 Ws (When, What, and Why?)}

\author{
Cristina Campoy ${ }^{a-c}$ Daniel Campos ${ }^{a, b}$ Tomás Cerdóa,b Estefanía Diéguez ${ }^{a, b}$ \\ José Antonio García-Santos ${ }^{a}$ b \\ a Department of Paediatrics, University of Granada, Granada, Spain; ${ }^{\text {b}}$ EURISTIKOS Excellence Centre for Paediatric

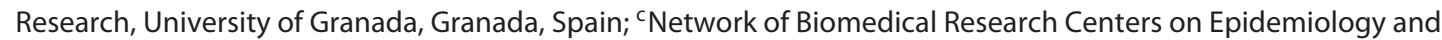 \\ Public Health (CIBERESP), ISCIII, Madrid, Spain
}

\section{Key Messages}

- Exclusive breastfeeding should be promoted for at least 4 months and is preferable for 6 months; according to infants' developmental and nutritional reasons, complementary feeding should not be introduced before 4 months and not delayed beyond 6 months.

- Complementary foods should meet the infants' nutritional requirements when breast milk does not provide them, and caregivers/parents should ensure a variety of foods with appropriate texture and consistency for the infants' developmental stage, promoting healthy food preferences.

- Fruit juices or sugar-sweetened beverages should be avoided during the first years of life. Also, no sugar or salt should be added to complementary foods.

- Iron-rich complementary foods including meat products and/or iron-fortified foods should be given to all children.

\section{Keywords}

Complementary feeding $\cdot$ Infants $\cdot$ Nutritional

requirements - Infants' health outcomes - Eating behavior .

Neurodevelopment $\cdot$ Microbiota

\begin{abstract}
While a wide knowledge exists on the effects of breast milk or infant formula on growth and infant development, less attention has been paid to the importance of complementary feeding (CF). This review focuses on current recommendations for optimal introduction of CF in healthy full-term European infants and discusses the potential impact of this type of feeding on health outcomes. Overall, exclusive breastfeeding is recommended at least for 4 months and preferable for 6 months, followed by the introduction of CF alongside breast milk; infants' nutrient requirements must meet the differences between nutrients provided by breast milk and the estimated total needs. There is growing evidence that healthy feeding practices during the CF period have positive short- and long-term effects on optimal growth, body composition, neurodevelopment, healthy food preferences, and gut microbiota composition and function; adequate and healthy CF may also diminish the
\end{abstract}

Cristina Campoy, Prof. MD

Department of Paediatrics, School of Medicine, University of Granada Avda. de la Investigación, 11

ES-18016 Granada (Spain)

E-Mail ccampoy@ugr.es 
risk of infections, allergies, type 1 diabetes mellitus, as well as celiac and non-communicable diseases. Following the expert recommendations, the design of nutritional strategies must encourage parents to provide a healthy lifestyle for their offspring. Future research should aim to optimize timing, content, and methods of CF; furthermore, it is necessary to explore future CF-targeted health-promoting strategies in early life (appetite regulation, eating patterns, eating behavior, gut dysbiosis, etc.) to prevent growth/obesity outcomes, immune system related-diseases or non-communicable diseases in later life.

(c) 2018 S. Karger AG, Basel

\section{Introduction}

Complementary feeding (CF) is defined as "the consumption of foods and liquids when breast milk or infant formula or follow-on formulas are no longer sufficient to meet the nutritional requirements of infants" $[1,2]$. During the CF period, marked changes in the diet with exposures to new foods, tastes, and feeding experiences take place. CF must provide optimal macro- and micronutrient intake not only to meet the infant's optimal growth and development during the first 2 years of life, but also to promote appropriate health outcomes in early and later life. The timing of introduction of $\mathrm{CF}$ and the nature of the foods to be given still remain under discussion. Moreover, current recommendations for $\mathrm{CF}$ are widely changeable between countries, reflecting the greater influences of cultural factors and food habits. Thus, further rigorous research as well as targeted programs and policies are needed. This review focuses on updating relevant insights in timing, content as well short- and long-term health effects of CF in healthy term-born infants.

\section{Timing and Content of $\mathrm{CF}$}

The "Optimal Window" for Introducing CF

Exclusive breastfeeding (EBF) means giving no other food or drink (not even water) to the infant except breast milk, oral replacement solution, drops and syrups consisting of vitamins, minerals supplements, or medicines. $\mathrm{EBF}$ is recommended until the age of 6 months, followed by the introduction of nutritionally adequate $\mathrm{CF}$ alongside breastfeeding up to 2 years or beyond to fill the gap in energy, iron, and other essential nutrients [3]. Although this recommendation is strongly supported by health policy-makers, the timing of introduction of CF varies considerably between low- and higher-income countries, and even within Europe depending on cultural habits. Only $37 \%$ of infants under 6 months of age in lowincome countries are exclusively breastfed, and introduction of CF is generally earlier than in high-income countries (around 1-3 months of life) [4]. CF practices in European countries also show EBF for 6 months in a minority of mothers, but there is higher frequency of EBF between 4 and 6 months compared with low-income countries [2]. The introduction of specific individual foods in European infants, however, meets dietary intakes of energy, macronutrients, sodium chloride, and potassium, and even generally exceeds them, but in some subgroups, the intake of specific nutrients such as $\mathrm{n}-3$ polyunsaturated fatty acids (PUFAs), vitamin D, or iodine is borderline [5]. To avoid the aforementioned situations, recommendation of EBF for 6 months and partial breastfeeding thereafter must be applied to populations rather than individuals, and CF should be introduced according to specific cultural and economic factors of the countries $[1,2]$. An effective way to achieve this goal is to implement multicomponent interventions from the pre- to postnatal period in which healthcare professionals and community are connected and involved [6]. To date, no effects on health or nutritional outcomes up to 12 months of age have been shown between introducing $\mathrm{CF}$ at 3-4 months or at 6 months of age [7].

\section{Developmental and Nutritional Reasons for Introducing $C F$}

The decision for introduction of CF is also determined by developmental growth and nutritional requirements of the infants. During the first years of life, the infant's diet becomes more varied and complex regarding food tastes and textures. These changes are closely related to physiological and neurodevelopmental maturation which allows infants to effectively metabolize milk food and cope with complex food textures [8] (Table 1). Interestingly, it is important to highlight that the European Society for Paediatric Gastroenterology, Hepatology, and $\mathrm{Nu}$ trition (ESPGHAN) Committee on Nutrition ( $\mathrm{CoN})$ suggests that 9-10 months of age is the critical window for introducing lumpy solid foods, and its introduction in later age is related to a high risk of feeding difficulties and unhealthy eating habits $[2,9]$. By $7-8$ months, parents should introduce finger food forms (soft cooked vegeta-
28

Ann Nutr Metab 2018;73(suppl 1):27-36 DOI: $10.1159 / 000490086$
Campoy/Campos/Cerdó/Diéguez/ García-Santos 
Table 1. Physiological and neurological maturation to determine the optimal introduction of complementary feeding

\begin{tabular}{ll}
\hline Age & Physiological/Neurological maturation \\
\hline At birth & Self-feeding based on nutritive suckling reflex \\
4 months & Child is able to metabolize nutrients due to maturation of renal and gastrointestinal function \\
$4-6$ months & Cortical and cognitive development improve tongue mobility, associated with increasing oral cavity volume \\
& $\begin{array}{l}\text { Progressive control of oral food transport } \\
\text { Motor skills required to accept and swallow pureed complementary feeding }\end{array}$ \\
6 months & Appearance of temporary inferior and superior incisors to handle biting \\
M-12 months & $\begin{array}{l}\text { Motor skills required to handle semisolid foods or self-feeding } \\
\text { Infant can drink from a cup using both hands }\end{array}$ \\
12-18 months & $\begin{array}{l}\text { Infant can eat adapted family foods } \\
\text { Appearance of molars improving intraoral food-mixing ability }\end{array}$ \\
\hline
\end{tabular}

bles and slices of soft fruit) while prolonged use of pureed foods should be avoided [10].

Breastfeeding by well-nourished mothers is suited to the nutrient needs of the infants up to 6 months, except for vitamin $\mathrm{K}$ and $\mathrm{D}[1,11]$. However, a recent European Food Safety Authority (EFSA) opinion paper [1] reported that the age at which breast milk does not cover the energy requirements anymore cannot be exactly defined. In fact, $525-574 \mathrm{kcal} /$ day is the mean metabolizable energy intake in EBF infants at 6 months, and $\sim 632-649 \mathrm{kcal} /$ day is the mean energy requirement [12]. However, using stable-isotope techniques to test infant energy balance, Nielsen et al. [13] showed that breast milk energy content remains unchanged despite higher milk intake in breastfed infants between 17 and 26 weeks of age.

As breast milk and infant formula certainly differ in composition and health effects, it might appear logical to give specific recommendations on CF for breastfed and formula-fed infants. For instance, micronutrient levels, such as iron or zinc, are higher in fortified infant formulas than in breast milk, which makes the choice of specific CF less critical in formula-fed infants [14]. Some evidence suggests that early CF introduction, before 4 months of age, has beneficial effects on iron stores and/or risk of iron deficiency and anemia $[15,16]$, but other methods can be used to optimize iron stores [17]. So, specific recommendations for $\mathrm{CF}$ introduction depending on the type of infant feeding (breast milk vs. formula) should be undertaken with caution to avoid practical problems and confusion among pediatricians and caregivers.

\section{Content of the CF Diet}

Based on observational and factorial approaches, nutrient requirements during $\mathrm{CF}$ in healthy full-term in-
Table 2. Current recommendations for nutrient requirements of complementary feeding

\begin{tabular}{ll}
\hline Nutrients & Dietary Reference Intakes (DRIs) \\
\hline Energy & $6-8$ months: $615 \mathrm{kcal} /$ day \\
& $9-11$ months: $686 \mathrm{kcal} /$ day \\
& $12-23$ months: $894 \mathrm{kcal} /$ day \\
Water & $0,8 \mathrm{~L} /$ day \\
Proteins & $10 \%$ total daily energy intake $(1.1 \mathrm{~g} / \mathrm{kg} /$ day $)$ \\
Carbohydrates & $45-60 \%$ of total daily energy intake \\
Fibers & $1-3$ years of age: $10 \mathrm{~g} /$ day \\
Total fat & $30-45 \%$ of total daily energy intake $($ not $<25 \%)$ \\
Saturated fat & $<10 \%$ of total daily energy intake \\
LC-PUFAs & $250 \mathrm{mg} /$ day \\
$\quad$ Linoleic acid & $4.6 \mathrm{~g} /$ day \\
a-Linolenic acid & $0.5 \mathrm{~g} /$ day \\
DHA & $100 \mathrm{mg} /$ day \\
Minerals & \\
$\quad$ Fe & $11 \mathrm{mg} /$ day \\
Zn & $3 \mathrm{mg} /$ day \\
Fat-soluble vitamins & \\
$\quad$ Vitamin A & $500 \mu \mathrm{g} /$ day \\
Vitamin D & $10 \mu \mathrm{g} /$ day \\
$\quad$ Vitamin K & $2.5 \mu \mathrm{g} /$ day \\
\hline
\end{tabular}

LC-PUFAs, long-chain polyunsaturated fatty acids; DHA, docosahexaenoic acid.

fants must be calculated as "the difference between the nutrients provided by breast milk and the estimated total needs" [2]. It is recommended to start with small quantities of food together with breast milk, increasing the amount when the infant is older (Table 2). According to WHO recommendations, complementary food should be offered 2-3 times per day at 6-8 months and 3-4 times per day at 9-24 months of age [18]. The current optimal amount of fat during the first months of life remains un- 
clear. The WHO recommends a range of $30-45 \%$ of total daily energy intake (approximately $30 \mathrm{~g} /$ day), while the EFSA advises $40 \%$ of total calories from 6 to less than 12 months and $35-40 \%$ from 12 to 24 months [18-20]. Saturated fat should be limited to less than $10 \%$ of the total energy intake and from 6 to 12 months of age the recommended intake of long-chain polyunsaturated fatty acids (LC-PUFAs) is $250 \mathrm{mg} /$ day, $4.6 \mathrm{~g} /$ day of linoleic acid, 0.5 $\mathrm{g}$ /day of a-linolenic acid, and $100 \mathrm{mg} /$ day of docosahexaenoic acid (DHA) [19-21].

According to the EFSA panel, the recommended daily intake of carbohydrates is $45-55 \%$ from 6 to 12 months followed by $45-60 \%$ to 36 months of age. Daily protein intake is approximately $10 \%$ of the total daily calories, with a recommendation of $1.1 \mathrm{~g} / \mathrm{kg} /$ day or $11 \mathrm{~g} /$ day for boys and $10 \mathrm{~g} /$ day for girls from 7 to 12 months, amounts that have been lowered to decrease the risk of obesity [1921]. There are no daily intake recommendations for fiber from 6 to 12 months of age. Regarding water intake, infants should drink about $0.8 \mathrm{~L}$ per day [19-21]. Micronutrient requirements are not met by breast milk after 6 months of EBF, especially iron, zinc, and fat-soluble vitamins $(A, D, K)$. The dietary reference intakes from 6 to 12 months of age are $11 \mathrm{mg} /$ day of iron [2], $3 \mathrm{mg} /$ day of zinc, $500 \mu \mathrm{g} /$ day of vitamin A, $10 \mu \mathrm{g} /$ day of vitamin D, and 2.5 $\mu \mathrm{g} /$ day of vitamin $\mathrm{K}[19,21]$.

\section{Interplay between the Timing of CF and Its Content}

Development of Taste and Food Preferences

Learning about food and eating occurs during the transition period from an exclusive milk diet to a solid diet. Infants have an inborn preference for sweet, salty, and umami tastes, but not for sour and bitter tastes [22]. Infants should be offered foods with a variety of flavors and textures including bittertasting green vegetables [2].

\section{"Baby-led weaning" has emerged as an alternative approach in which infants are sharing family foods and feeding themselves with hand-held foods}

\section{"Baby-Led Weaning" and Parenting Style}

It is known that during $\mathrm{CF}$, both the way chosen to give the food and the parent-infant relationship may have an important role in the development of dietary preferences and appetite regulation. Traditionally, infants consume their first solid foods using spoon-feeding in the form of purees given by parents, with subsequent introduction of semisolid and finger foods as complementary diet from 8 months [27]. However, over the last 10-15 years, "baby-led weaning" (BLW) has emerged as an alternative approach in which infants are sharing family foods and feeding themselves with handheld foods [27]. This method may provide a range of benefits to the infants, including better infant autonomy and control over their intake, eating patterns to encourageresponsiveparenting, and even reduce the risk of overweight and obesity in later life $[21,28]$. Recent studies Newborns also innately prefer sugar solutions to water, but this preference may change at 6 months according to the infants' dietary experience [23]. In addition, young infants show a high predilection for energy-dense foods rather than "healthy foods," with the consequent risk of overweight and obesity at earlier ages [22]. Certainly, the genetic base strongly drives taste and food preferences, although these can also be modified by early nutrient experiences related to food availability as well as cultural and parental influences $[24,25]$. In recent show no differences in frequency of choking [29], body mass index [30], and energy intake [31] between BLW and traditional feeding practices. Another similar approach, the "baby-led introduction to solids" (BLISS), has been developed to address potential concerns with iron status, choking, and growth faltering [32]. BLISS infants showed less food fussiness and better enjoyment of food compared to infants who were spoon-fed, but it did not result in a more appropriate body weight than the traditional feeding method [33].
Campoy/Campos/Cerdó/Diéguez/ García-Santos 
It is evident that the parent-infant relationship, in terms of attitudes and behaviors, will play a major role in the infant's feeding practices acquisition. There is a close direct and indirect association between optimal nutritional education of caregivers/parents and lower risk of overweight and obesity in early life [34]. It has been reported that an authoritative feeding style and healthy nutrition behavior are related to better infant nutritional behavior [34], while restrictive feeding practices based on maternal infant weight perception and concerns are positively associated with higher weightlength gain during the first year of life and subsequent obesity risk during childhood [35]. These findings, however, have been obtained from observational studies which involved toddlers rather than infants, and further intervention studies are required to achieve stronger conclusions.

\section{Specific Dietary Practices and Available Foods for Infants and Toddlers}

At the beginning of CF, parents may choose between home- and commercially prepared infant foods, which not only differ in their preparation but also in flavors, textures, energy density, and nutrient content, especially in sugar and salt [36]. As a consequence, appropriate choices between both types of prepared foods might have a major role in later development of healthy eating patterns and risk of non-communicable diseases. Data from the German DONALD cohort suggest that offering homemade CF or commercial CF without added sugar might reduce sugar intake at later life [37]. This study also suggests that intake of commercial CF clearly impacts individual taste and food preferences by predetermining a decreased fruit and vegetable intake in infancy [38]. As the usage of commercially CF is very pervasive in developed countries, it is important to emphasize the need for longitudinal studies to draw firm conclusions on beneficial or unfavorable effects of commercial infant foods on health outcomes.

Finally, special attention should be given to vegetarian and vegan diets especially during the first 2 years of life as infants and children may become deficient in essential nutrients including iron, zinc, calcium, DHA, protein, and vitamins $\mathrm{A}, \mathrm{D}, \mathrm{B}_{2}$, and $\mathrm{B}_{12}$. Current recommendations suggest that $\mathrm{CF}$ based on a vegan diet in infants and young children should be done under medical and nutritional supervision providing appropriate supplementation during pregnancy and lactation and the intake of vegan products high in protein and energy [2].

Complementary Feeding in Developed

Countries

\section{Effects of CF on Health Outcomes}

\section{Growth and Body Composition}

There is growing evidence that early food habits have a programming effect on later health outcomes. There is an inverse relationship between breastfeeding and risk of overweight/obesity in early childhood; sustained breastfeeding to 12 months and beyond is associated with a healthy weight status in early childhood. These associations seem to be independent of socioeconomic determinants, maternal prepregnancy BMI, smoking in pregnancy, delivery method, infant birth weight, and age at which solid food was introduced [39].

Both CF and follow-on formulas should avoid excessive protein content but meet micro- and macronutrient intake to reach a healthy weight gain and subsequent lower obesity risk during infancy $[40,41]$. In this regard, recent data from the ALSPAC cohort showed that high cows' milk consumption is associated with a faster weight gain at 18 months. Infants at 8 months who had a high intake of cows' milk had higher mean energy, protein, and fat intakes compared to breastfed infants. Most of the RCTs and observational studies performed have shown no association between the timing of introduction of CF and later obesity risk [42]. Other studies suggested that age-inappropriate $\mathrm{CF}$ negatively influences energy intake and infant weight-for-length, which may increase longterm obesity risk by shaping infant appetite, food preferences, and metabolism [43]. These findings support that early-life intake may have a programming effect with an important impact on growth and body composition through childhood [44]. Thus, new approaches should encourage the introduction of CF after 4 completed months with ongoing breastfeeding to avoid adverse health outcomes in infants living in high-income countries [45].

\section{Neurodevelopment}

No differences in IQ at 6 years of age have been found between children who received EBF for 3 months versus 6 months [46]. Vitamins $\mathrm{B}_{6}, \mathrm{~B}_{12}$, and $\mathrm{B}_{9}$ (folate), choline, iodine, selenium, iron, and zinc are critical for brain development and are found in animal-source foods, especially flesh foods. Iodine and LC-PUFAs are the exceptions. During the CF period, even with continued breastfeeding, primary reliance on unfortified plant-based staple foods and/or lower bioavailability often results in inadequate intake of several critical micronutrients. Undoubtedly, suboptimal CF quality and quantity contribute to poor linear growth and neurodevelopment, even though total energy intake may be adequate [47]. CF should include DHA, arachidonic acid, other PUFAs, saturated fatty acids, and complex

Ann Nutr Metab 2018;73(suppl 1):27-36 DOI: $10.1159 / 000490086$ 
lipids found in milk fat; DHA status usually decreases during the CF period due to decrease and discontinuation of breast milk. A cross-sectional study showed that adequate blood DHA status in late infancy is determined by breastfeeding, fatty acid dehydrogenase genotype, and fish intake [48]. Two additional trials investigated the role of LCPUFA-supplemented infant formula during the CF period. Infants were randomized to LC-PUFA-supplemented versus unsupplemented formula when they stopped breastfeeding at either 6 weeks of age or 4-6 months of age [4950]. Both trials concluded that infants who received LCPUFA-supplemented formula had significantly better visual acuity up to 1 year, i.e., better neurodevelopment.

In addition, the quality of $\mathrm{CF}$ and caregiver responsiveness is also critical for optimal infant and young child neurodevelopment. However, interventions investigating the impact of improving the quality of the CF process specifically on neurodevelopment are limited in low-resource settings. A RCT employing lipid-based nutrient supplements or a micronutrient-fortified corn-soy flour in Malawian infants reported that length-for-age $z$-score gain and maternal education were both significant predictors of developmental outcomes [51]. In a clinical trial studying Indian toddlers, guidance around CF practices in addition to psychosocial stimulation had a significant positive effect on the toddlers' neurodevelopment [52]. These findings support the critical importance of maternal education for fostering enhanced child psychosocial stimulation, improved feeding practices, and improved nutritional status on child development, with or without a substantial impact on linear growth [53].

\section{Establishment and Composition of Gut Microbiota}

Gut microbiota suffers profound modifications from birth to adulthood, characterized by a dominance of Firmicutes and Bacteroidetes in adults, while Actinobacteria, Firmicutes, and Proteobacteria predominate in infants' gut microbiota and Bacteroidetes are absent [54].

Early nutrition during the first months of life as well as CF might have a major role in adult-like gut microbiota development [55]. It has been suggested that gut dysbiosis during early life (or imbalance in gut microbiota determined by different factors such as infections, antibiotics, etc.) could be prevented or reversed during the CF period by the development of healthy nutritional patterns. The evolutional trajectory of gut microbiota from birth has been shown to prime for health later in life [56-60]. Different studies have shown that the initial microbiota evolves over time, increasing diversity and adapting to the colonic anaerobic environment and nutrient availability. In fact, aerobic bacteria at birth are replaced by anaerobic bacteria involved in lactate metabolism during lactation, followed during the CF period by maternal-like bacteria involved in fiber and carbohydrate degradation and short-chain fatty acid production [55]. These changes dramatically occur from 9 to 36 months of life, and the optimal establishment of adult-like microbiota is mostly driven by the infant's nutrient intake [61].

Research efforts are being focused on the relationship between CF, microbiota, and risk of overweight or obesity in later life. Available data suggest that the timing of introduction of CF was not related to microbial abundances or diversity at 9 months and changes in the gut microbiota are mostly driven by protein and fiber dietary contents [62]. Interestingly, these food-related changes affected bacterial groups which were not predictive of weight gain [61]. Thus, further longitudinal studies should be carried out to better understand the mechanisms underlying timing and content of CF on the development of the infants' gut microbiota as well their potential role in long-term health outcomes.

\section{CF and Immune System-Related Diseases}

Infections

Immunoactive molecules present in breast milk are involved in the development of the infants' immune system. Recent studies have suggested that more prolonged EBF may be associated with a reduced risk of respiratory infections and hospitalization for infection, including infants living in high-income countries [11, 63]. Moreover, delayed initiation of breastfeeding has been associated with an increased risk of several common infectious morbidities in early infancy, including upper respiratory infection and vomiting [64]. However, the timing of introduction of CF has not been clearly associated with the risk of infections [2]. On the other hand, the timing of introduction of infant formula seems to be a bet-

ter predictor than introduction of CF for high risk of infections during infancy and preschool age [63-64]. It is also important to highlight that CF must be prepared under safe conditions and should contain optimal levels of specific nutrients such as vitamin A, iron, and zinc, as deficiencies of these micronutrients are linked to immuno-

Campoy/Campos/Cerdó/Diéguez/ García-Santos 
Table 3. Current recommendations for key topics in complementary feeding in healthy full-term infants

\begin{tabular}{|c|c|c|c|c|c|c|c|c|c|c|c|c|c|c|c|c|c|c|c|}
\hline \multirow[t]{2}{*}{ Complementary feeding } & \multicolumn{19}{|c|}{ Timing (months) } \\
\hline & 0 & 1 & 2 & 3 & 4 & 5 & 6 & 7 & 8 & 9 & 10 & 11 & 12 & 13 & 14 & 15 & 16 & 17 & 18 \\
\hline \multicolumn{20}{|l|}{ Timing } \\
\hline Exclusive breastfeeding & $\mathrm{x}$ & $\mathrm{x}$ & $\mathrm{x}$ & $\mathrm{x}$ & $\mathrm{x}$ & $\mathrm{x}$ & $\mathrm{x}$ & & & & & & & & & & & & \\
\hline Complementary feeding & & & & & $\mathrm{x}$ & $\mathrm{x}$ & $\mathrm{x}$ & $\mathrm{x}$ & $\mathrm{x}$ & $\mathrm{x}$ & $\mathrm{x}$ & $\mathrm{x}$ & $\mathrm{x}$ & $\mathrm{x}$ & $\mathrm{x}$ & $\mathrm{x}$ & $\mathrm{x}$ & $\mathrm{x}$ & $\mathrm{x}$ \\
\hline \multicolumn{20}{|l|}{ Content } \\
\hline Cow’s milk & & & & & & & & & & & & & $\mathrm{x}$ & $\mathrm{x}$ & $\mathrm{x}$ & $\mathrm{x}$ & $\mathrm{x}$ & $\mathrm{x}$ & $\mathrm{x}$ \\
\hline \multicolumn{20}{|l|}{ Allergy foods } \\
\hline Peanut & & & & & $\mathrm{x}$ & $\mathrm{x}$ & $\mathrm{x}$ & $\mathrm{x}$ & $\mathrm{x}$ & $\mathrm{x}$ & $\mathrm{x}$ & $\mathrm{x}$ & & & & & & & \\
\hline Gluten & & & & & $\mathrm{x}$ & $\mathrm{x}$ & $\mathrm{x}$ & $\mathrm{x}$ & $\mathrm{x}$ & $\mathrm{x}$ & $\mathrm{x}$ & $\mathrm{x}$ & $\mathrm{x}$ & & & & & & \\
\hline \multicolumn{20}{|l|}{ Methods } \\
\hline Pureed foods & & & & & $\mathrm{x}$ & $\mathrm{x}$ & $\mathrm{x}$ & $\mathrm{x}$ & & & & & & & & & & & \\
\hline Lumpy foods & & & & & & & & & $\mathrm{x}$ & $\mathrm{x}$ & $\mathrm{x}$ & $\mathrm{x}$ & $\mathrm{x}$ & & & & & & \\
\hline Solid foods & & & & & & & & & & & & & & $\mathrm{x}$ & $\mathrm{x}$ & $\mathrm{x}$ & $\mathrm{x}$ & $\mathrm{x}$ & $\mathrm{x}$ \\
\hline
\end{tabular}

All infants should receive iron-rich complementary foods or supplements to avoid iron deficiency. No sugar or salt should be added. Fruit juices or sugar-sweetened beverages should be avoided. In case of vegan diets, and under medical or dietetic supervision, infants should receive supplements of vitamin $B_{12}$, vitamin $D$, iron, zinc, folate, $n-3$ long-chain polyunsaturated fatty acids, protein, and calcium.

deficiencies and provide a window of opportunity for infective agents [65].

\section{Allergy}

To elucidate the role of CF in the development of allergies, several studies have demonstrated that early and repeated exposure to an antigen during critical windows leads to optimal development of immunotolerance [66]. As a consequence, regimens currently recommended by several National Institutes of Health actively encourage the early introduction of potential common food allergens, such as peanut and egg, at approximately 6 months of age, but not before 4 months of age [67]. For instance, early introduction of peanuts significantly decreased but did not nullify peanut allergy risk. In contrast, delayed peanut introduction may increase the risk of peanut allergy [67]. Accordingly, healthcare providers should recommend early peanut introduction at 4-11 months in those infants living in countries where peanut allergy is prevalent or are at a high risk for peanut allergy and be followed up by an appropriately trained specialist. On the other hand, food containing egg should be introduced between 4 and 6 months. Whole cows' milk should not be used as the main drink before 12 months of age [2].

In general, allergenic foods should be introduced at any time after 4 months independently of the family's history risk $[2,68]$.

Complementary Feeding in Developed Countries

\section{Celiac Disease}

Celiac disease (CD) is a long-term autoimmune disorder primarily affecting the small intestine that occurs in genetically susceptible individuals triggered by the ingestion of gluten. The ESPGHAN CoN initially stated that gluten introduction should take place during breastfeeding between 4 and 7 months of age to reduce the risk of CD [9]. Further studies, however, strongly support that the timing of introduction of gluten or its introduction at any time during breastfeeding had no beneficial effect on the primary prevention of $\mathrm{CD}$ in children at genetic risk for this pathology [69-70]. As a consequence, current ESPGHAN CoN recommendations suggest the following [2]: (1) the risk of CD is not associated with the timing of gluten introduction or with any amount of breastfeeding or no breastfeeding; (2) the timing of gluten introduction should occur between the ages of 4 and 12 months; and (3) large amounts of gluten should not be consumed during the first week after gluten introduction and during the first year of life [71]. Data from the PreventCD trial suggest that both the gluten consumption pattern and quantities of gluten consumed at 11-36 months of age are not related to the risk of CD development. The risk is also not affected by the interaction between gluten intake and genetic risk alleles for CD [72]. Research efforts must be increased not only to quantify the amount of gluten to be introduced dur- 
ing CF and infancy, but also to evaluate the potential role of risk alleles and gluten intake in CD risk in early infancy.

\section{Type 1 Diabetes Mellitus}

Cow's milk and sugar consumption has been associated with an increased risk of preclinical and/or clinical type 1 diabetes mellitus (T1D), with a progression from preclinical to clinical disease. Breast milk, on the other hand, may be protective. Processed foods may be related to a greater risk of T1D because they contain higher amounts of advanced glycation end products. Nitrites or $\mathrm{N}$-nitrous compounds in processed meat products could increase the risk of this disease. Among nutrients, n-3 fatty acids, vitamins $\mathrm{D}$ and $\mathrm{E}$, and zinc may protect from preclinical and/or clinical T1D. Food microbial composition or the foods' effects on gut microbiota are receiving increased attention, also due to their putative role in the development of T1D. The number of prospective studies in this research field is limited and most of the findings remain to be replicated.

A recent systematic review [73] evaluated the potential role of infant feeding practices in later development of T1D. Available data support that EBF during gluten introduction at $>3$ months does not reduce the risk of T1D in childhood, while EBF at the time of cereal introduction decreases this risk. On the other hand, both observational and randomized interventional studies also suggest that early introduction of gluten ( $<3$ months) and sugarsweetened beverages are associated with increased risk of T1D in later life. Further RCTs should be performed to extend the knowledge of the relationship between timing and content of CF and risk of T1D.

\section{Cardiovascular Disease}

There is controversy as to whether the timing and content of CF may influence the risk of cardiovascular disease in later life. The PROBIT study that followed children up to the age of 6.5 years showed that EBF duration had no effect on blood pressure [2]. In contrast, other studies broadly support that longer breastfeeding, but $<24$ months, and subsequent delayed introduction of CF were related to lower waist circumference and blood pressure in early life $[74,75]$. Recent studies have also evaluated the specific role of LC-PUFA and fat intake during CF in later cardiometabolic health. Infants aged 9 months who were supplemented with fish oil for 3 months had lower systolic blood pressure but higher plasma cholesterol and low-density lipoprotein cholesterol [76]. Moreover, follow-up of children from the Generation R study at 6 years reported no effects of intake of different types of fatty acids on cardiometabolic health, while a high-fiber diet was related to better outcomes in terms of high-density lipoprotein cholesterol and triglycerides $[77,78]$.

\section{Current Recommendations and Conclusions}

It is clear that CF is an important stage in the transition from breastfeeding to family foods, which comprises a critical period for infant growth and development. Therefore, CF should meet nutritional requirements at this age stage, avoiding nutritional deficiencies or nonoptimal introduction of certain types of foods because of their subsequent negative effects on early and later health (Table 3). Recommendations on CF should be based on food availability and cultural factors of the population. To achieve this goal, however, further research should focus on better knowledge about the content, timing, and health outcomes of CF. It is also important to highlight that these recommendations should be implemented through multicomponent approaches involving healthcare professionals, community, and parents, emphasizing broader aspects of a healthy lifestyle for the infant.

\section{Disclosure Statement}

The authors declare that no financial nor other conflict of interest exists in relation to the content of the paper. The writing of this article was supported by Nestlé Nutrition Institute.

\section{References}

1 EFSA Panel on Dietetic Products, Nutrition and Allergies (NDA): Scientific opinion on the appropriate age for introduction of complementary feeding of infants. EFSA J 2009;7: 1423.

2 Fewtrell M, Bronsky J, Campoy C, Domellof M, Embleton N, Fidler MN, et al: Complementary feeding: a position paper by the European Society for Paediatric Gastroenterology, Hepatology, and Nutrition (ESPGHAN) Committee on Nutrition. J Pediatr Gastroenterol Nutr 2017;64:119-32.

3 WHO (World Health Organization): Complementary Feeding. Report of the Global Consultation. Geneva, 10-13 December 2001. Summary of Guiding Principles.

4 Victora CG, Bahl R, Barros AJ, Franca GV Horton S, Krasevec J, et al: Breastfeeding in the 21st century: epidemiology, mechanisms, and lifelong effect. Lancet 2016;387:475-90.
Campoy/Campos/Cerdó/Diéguez/ García-Santos 
5 EFSA NDA Panel (EFSA Panel on Dietetic Products, Nutrition and Allergies): Scientific opinion on nutrient requirements and dietary intakes of infants and young children in the European Union. EFSA J 2013;11:3408.

6 Kim SK, Park S, Oh J, Kim J, Ahn S: Interventions promoting exclusive breastfeeding up to six months after birth: A systematic review and meta-analysis of randomized controlled trials. Int J Nurs Stud 2018;80:94-105.

7 Mehta KC, Specker BL, Bartholmey S, Giddens J, Ho ML: Trial on timing of introduction to solids and food type on infant growth. Pediatrics 1998;102:569-73.

8 Nicklaus S, Demonteil L, Tournier C: Modifying the texture of foods for infants and young children, in Chen J, Rosenthal A (eds.): Modifying Food Texture Volume 2: Sensory Analysis, Consumer Requirements and Preferences. London, Woodhead, 2015, pp 187222.

9 Agostoni C, Decsi T, Fewtrell M, Goulet O, Kolacek S, Koletzko B, et al: Complementary feeding: a commentary by the ESPGHAN Committee on Nutrition. J Pediatr Gastroenterol Nutr 2008;46:99-110.

10 Marduel BA, Vernet M: Introduction of new food textures during complementary feeding: observations in France. Arch Pediatr 2018;25: 6-12.

11 Prell C, Koletzko B: Breastfeeding and complementary feeding. Dtsch Arztebl Int 2016; 113:435-444.

12 Reilly JJ, Wells JC: Duration of exclusive breast-feeding: introduction of complementary feeding may be necessary before 6 months of age. Br J Nutr 2005;94:869-872.

13 Nielsen SB, Reilly JJ, Fewtrell MS, Eaton S, Grinham J, Wells JC: Adequacy of milk intake during exclusive breastfeeding: a longitudinal study. Pediatrics 2011;128:e907-e914.

14 Gould JF: Complementary feeding, micronutrients and developmental outcomes of children. Nestle Nutr Inst Workshop Ser 2017;87: $13-28$.

15 Jonsdottir OH, Thorsdottir I, Hibberd PL, Fewtrell MS, Wells JC, Palsson GI, et al: Timing of the introduction of complementary foods in infancy: a randomized controlled trial. Pediatrics 2012;130:1038-1045.

16 Somasse YE, Dramaix M, Traore B, Ngabonziza I, Toure $\mathrm{O}$, Konate $\mathrm{M}$, et al: The WHO recommendation of home fortification of foods with multiple-micronutrient powders in children under 2 years of age and its effectiveness on anaemia and weight: a pragmatic cluster-randomized controlled trial. Public Health Nutr 2018;21:1350-1358.

17 Libuda L, Hilbig A, Berber-Al-Tawil S, Kalhoff $\mathrm{H}$, Kersting M: Association between full breastfeeding, timing of complementary food introduction, and iron status in infancy in Germany: results of a secondary analysis of a randomized trial. Eur J Nutr 2018;57:523531.

18 Dewey K: Guiding principles for complementary feeding of the breastfed child. 2002.
Available from: http://www.who.int/nutrition/publications/guiding_principles_compfeeding_breastfed.pdf.

19 Dietary Reference Intakes for Calcium, Phosphorous, Magnesium, Vitamin D, and Fluoride (1997); Thiamin, Riboflavin, Niacin, Vitamin $\mathrm{B}_{6}$, Folate, Vitamin $\mathrm{B}_{12}$, Pantothenic Acid, Biotin, and Choline (1998); Vitamin C, Vitamin E, Selenium, and Carotenoids (2000); Vitamin A, Vitamin K, Arsenic, Boron, Chromium, Copper, Iodine, Iron, Manganese, Molybdenum, Nickel, Silicon, Vanadium, and Zinc (2001); Water, Potassium, Sodium, Chloride, and Sulfate (2005); Calcium and Vitamin D (2011). Available from: www. nap.edu.

20 Agostoni C, Berni Canani R, FairweatherTait S, Heinonen M, Korhonen H, La Vieille $S$, et al: Scientific Opinion on nutrient requirements and dietary intakes of infants and young children in the European Union: EFSA Panel on Dietetic Products, Nutrition and Allergies (NDA). EFSA J 2013;11:3408.

21 Alvisi P, Brusa S, Alboresi S, Amarri S, Bottau P, Cavagni $G$, et al: Recommendations on complementary feeding for healthy, full-term infants. Ital J Pediatr 2015;41:36.

22 Fidler MN, Braegger C, Bronsky J, Campoy C, Domellof M, Embleton ND, et al: Sugar in infants, children and adolescents: a position paper of the european Society for Paediatric Gastroenterology, Hepatology and Nutrition Committee on Nutrition. J Pediatr Gastroenterol Nutr 2017;65:681-696.

23 Mennella JA, Bobowski NK: The sweetness and bitterness of childhood: insights from basic research on taste preferences. Physiol Behav 2015;152:502-507.

24 Larsen JK, Hermans RC, Sleddens EF, Engels RC, Fisher JO, Kremers SP: How parental dietary behavior and food parenting practices affect children's dietary behavior. Interacting sources of influence? Appetite 2015;89:246257.

25 Nekitsing C, Hetherington MM, BlundellBirtill P: Developing healthy food preferences in preschool children through taste exposure, sensory learning, and nutrition education. Curr Obes Rep 2018;7:60-67.

26 Remy E, Issanchou S, Chabanet C, Nicklaus S: Repeated exposure of infants at complementary feeding to a vegetable puree increases acceptance as effectively as flavor-flavor learning and more effectively than flavor-nutrient learning. J Nutr 2013;143:1194-1200.

27 Jones S: A history of baby-led weaning: the evolution of complementary feeding trends. J Health Visit 2016;4:524-530.

28 Brown A, Jones SW, Rowan H: Baby-led weaning: the evidence to date. Curr Nutr Rep 2017;6:148-156.

29 Brown A: No difference in self-reported frequency of choking between infants introduced to solid foods using a baby-led weaning or traditional spoon-feeding approach. J Hum Nutr Diet 2017, DOI: 10.1111/jhn. 12528, Epub ahead of print.
30 Kumar G: Baby-led weaning did not significantly impact body mass index when compared with traditional spoon-feeding. Arch Dis Child Educ Pract 2018;103:222.

31 Morison BJ, Taylor RW, Haszard JJ, Schramm CJ, Williams EL, Fangupo LJ et al: How different are baby-led weaning and conventional complementary feeding? A cross-sectional study of infants aged 6-8 months. BMJ Open 2016;6:e010665.

32 Daniels L, Heath AL, Williams SM, et al: Baby-Led Introduction to SolidS (BLISS) study: a randomised controlled trial of a baby-led approach to complementary feeding. BMC Pediatr 2015;15:179.

33 Taylor RW, Williams SM, Fangupo LJ, Wheeler BJ, Taylor BJ, Daniels L, et al: Effect of a baby-led approach to complementary feeding on infant growth and overweight: a randomized clinical trial. JAMA Pediatr 2017; 171:838-846.

34 Redsell SA, Edmonds B, Swift JA, Siriwardena AN, Weng S, Nathan D, et al: Systematic review of randomised controlled trials of interventions that aim to reduce the risk, either directly or indirectly, of overweight and obesity in infancy and early childhood. Matern Child Nutr 2016;12:24-38.

35 Harrison M, Brodribb W, Davies PSW, Hepworth J: Impact of Maternal Infant Weight Perception on Infant Feeding and Dietary Intake. Matern Child Health J 2018;22:11351145.

36 Maslin K, Venter C: Nutritional aspects of commercially prepared infant foods in developed countries: a narrative review. Nutr Res Rev 2017;30:138-148.

37 Foterek K, Buyken AE, Bolzenius K, Hilbig A, Nothlings U, Alexy U: Commercial complementary food consumption is prospectively associated with added sugar intake in childhood. Br J Nutr 2016;115:2067-2074.

38 Foterek K, Hilbig A, Alexy U: Associations between commercial complementary food consumption and fruit and vegetable intake in children. Results of the DONALD study. Appetite 2015;85:84-90.

39 Bell S, Yew SSY, Devenish G, Ha D, Do L, Scott J: Duration of breastfeeding, but not timing of solid food, reduces the risk of overweight and obesity in children aged 24 to 36 months: findings from an Australian Cohort Study. Int J Environ Res Public Health 2018; 15:E599.

40 Monteiro PO, Victora CG: Rapid growth in infancy and childhood and obesity in later life - a systematic review. Obes Rev 2005;6: 143-154.

41 Ong KK, Loos RJ: Rapid infancy weight gain and subsequent obesity: systematic reviews and hopeful suggestions. Acta Paediatr 2006; 95:904-908.

42 Daniels L, Mallan KM, Fildes A, Wilson J: The timing of solid introduction in an 'obesogenic' environment: a narrative review of the evidence and methodological issues. Aust NZ J Public Health 2015;39:366-373. 
43 Thompson AL, Bentley ME: The critical period of infant feeding for the development of early disparities in obesity. Soc Sci Med 2013; 97:288-296.

44 Hopkins D, Steer CD, Northstone K, Emmett PM: Effects on childhood body habitus of feeding large volumes of cow or formula milk compared with breastfeeding in the latter part of infancy. Am J Clin Nutr 2015;102:10961103.

45 Agostoni C, Przyrembel H: The timing of introduction of complementary foods and later health; in Szajewska H, Shamir R (eds): Evidence-Based Research in Pediatric Nutrition. World Rev Nutr Diet. Basel, Karger, 2013, vol 108, pp 63-70.

46 Kramer MS, Matush L, Bogdanovich N, Aboud F, Mazer B, Fombonne E, et al: Health and development outcomes in 6.5-y-old children breastfed exclusively for 3 or $6 \mathrm{mo}$. Am J Clin Nutr 2009;90:1070-1074.

47 Krebs NF, Lozoff B, Georgieff MK: Neurodevelopment: the impact of nutrition and inflammation during infancy in low-resource settings. Pediatrics 2017;139(suppl 1):S50 S58.

48 Harslof LB, Larsen LH, Ritz C, Hellgren LI, Michaelsen KF, Vogel U, et al: FADS genotype and diet are important determinants of DHA status: a cross-sectional study in Danish infants. Am J Clin Nutr 2013;97:14031410 .

49 Birch EE, Hoffman DR, Castaneda YS, Fawcett SL, Birch DG, Uauy RD: A randomized controlled trial of long-chain polyunsaturated fatty acid supplementation of formula in term infants after weaning at $6 \mathrm{wk}$ of age. Am J Clin Nutr 2002;75:570-580

50 Hoffman DR, Birch EE, Castaneda YS, Fawcett SL, Wheaton DH, Birch DG, et al: Visual function in breast-fed term infants weaned to formula with or without long-chain polyunsaturates at 4 to 6 months: a randomized clinical trial. J Pediatr 2003;142:669-677.

51 Phuka JC, Gladstone M, Maleta K, Thakwalakwa C, Cheung YB, Briend A, Manary MJ, Ashorn P: Developmental outcomes among 18-month-old Malawians after a year of complementary feeding with lipid-based nutrient supplements or corn-soy flour. Matern Child Nutr 2012;8:239-248.

52 Vazir S, Engle P, Balakrishna N, Griffiths PL, Johnson SL, Creed-Kanashiro H, Fernandez Rao S, Shroff MR, Bentley ME: Cluster-randomized trial on complementary and responsive feeding education to caregivers found improved dietary intake, growth and development among rural Indian toddlers. Matern Child Nutr 2013;9:99-117.

53 Bhutta ZA, Das JK, Rizvi A, Gaffey MF, Walker N, Horton S, Webb P, Lartey A, Black RE; Lancet Nutrition Interventions Review Group; Maternal and Child Nutrition Study
Group: Evidence-based interventions for improvement of maternal and child nutrition: what can be done and at what cost? Lancet 2013;382:452-477.

54 Hesla HM, Stenius F, Jaderlund L, Nelson R, Engstrand L, Alm J, et al: Impact of lifestyle on the gut microbiota of healthy infants and their mothers-the ALADDIN birth cohort. FEMS Microbiol Ecol 2014;90:791-801.

55 Backhed F, Roswall J, Peng Y, Feng Q, Jia H, Kovatcheva-Datchary P, et al: Dynamics and stabilization of the human gut microbiome during the first year of life. Cell Host Microbe 2015;17:852.

56 Cryan JF, Dinan TG: Mind-altering microorganisms: the impact of the gut microbiota on brain and behaviour. Nat Rev Neurosci 2012; 13:7016712.

57 Cox LM, Yamanishi S, Sohn J, Alekseyenko $\mathrm{AV}$, Leung JM, Cho I, et al: Altering the intestinal microbiota during a critical developmental window has lasting metabolic consequences. Cell 2014;158:7056721.

58 Cerdó T, García-Valdés L, Altmae S, Ruiz A, Suárez A, Campoy C: Role of microbiota function during early life on child's neurodevelopment. Trends Food Sci Technol 2016;57: 273-288.

59 Cerdó T, Ruiz A, Jáuregui R, Azaryah H, Torres-Espínola FJ, García-Valdés L, Teresa Segura M, Suárez A, Campoy C: Maternal obesity is associated with gut microbial metabolic potential in offspring during infancy. J Physiol Biochem 2018;74:159-169.

60 Tamburini S, Shen N, Wu HC, Clemente JC: The microbiome in early life: implications for health outcomes. Nat Med 2016;22:713-722.

61 Bergstrom A, Skov TH, Bahl MI, Roager HM, Christensen LB, Ejlerskov KT, et al: Establishment of intestinal microbiota during early life: a longitudinal, explorative study of a large cohort of Danish infants. Appl Environ Microbiol 2014;80:2889-2900.

62 Laursen MF, Andersen LB, Michaelsen KF, Molgaard C, Trolle E, Bahl MI, Licht TR: Infant gut microbiota development is driven by transition to family foods independent of maternal obesity. mSphere 2016;1:e0069-15.

63 Tromp I, Kiefte-de JJ, Raat H, Jaddoe V, Franco O, Hofman A, et al: Breastfeeding and the risk of respiratory tract infections after infancy: the Generation R study. PLoS One 2017; 12:e0172763.

64 Smith ER, Locks LM, Manji KP, McDonald CM, Kupka R, Kisenge R, et al: Delayed breastfeeding initiation is associated with infant morbidity. J Pediatr 2017;191:57-62.

65 Calder PC, Jackson AA: Undernutrition, infection and immune function. Nutr Res Rev 2000;13:3-29.

66 Chipps BE: Randomized trial of peanut consumption in infants at risk for peanut allergy. Pediatrics 2015;136:S238-S239.
67 Du TG, Sampson HA, Plaut M, Burks AW, Akdis CA, Lack G: Food allergy: update on prevention and tolerance. J Allergy Clin Immunol 2018;141:30-40.

68 West C: Introduction of complementary foods to infants. Ann Nutr Metab 2017; 70(suppl 2):47-54.

69 Szajewska H, Shamir R, Chmielewska A Piescik-Lech M, Auricchio R, Ivarsson A, et al: Systematic review with meta-analysis: early infant feeding and coeliac disease - update 2015. Aliment Pharmacol Ther 2015;41: 1038-1054.

70 Vriezinga SL, Auricchio R, Bravi E, Castillejo G, Chmielewska A, Crespo-Escobar P, et al: Randomized feeding intervention in infants at high risk for celiac disease. N Engl J Med 2014;371:1304-1315.

71 Szajewska H, Shamir R, Mearin L, RibesKoninckx C, Catassi C, Domellof M, et al: Gluten introduction and the risk of coeliac disease: a position paper by the European Society for Pediatric Gastroenterology, Hepatology, and Nutrition. J Pediatr Gastroenterol Nutr 2016;62:507-513.

72 Crespo-Escobar P, Mearin ML, Hervas D, Auricchio R, Castillejo G, Gyimesi J, et al: The role of gluten consumption at an early age in celiac disease development: a further analysis of the prospective PreventCD cohort study. Am J Clin Nutr 2017;105:890-896.

73 Meijer CR, Discepolo V, Troncone R, Mearin ML: Does infant feeding modulate the manifestation of celiac disease and type 1 diabetes? Curr Opin Clin Nutr Metab Care 2017;20: 222-226.

74 Wong PD, Anderson LN, Dai DDW, Parkin PC, Maguire JL, Birken CS: The association of breastfeeding duration and early childhood cardiometabolic risk. J Pediatr 2018;192:8058.

75 de Beer M, Vrijkotte TG, Fall CH, van EM, Osmond C, Gemke RJ: Associations of infant feeding and timing of weight gain and linear growth during early life with childhood blood pressure: findings from a prospective population based cohort study. PLoS One 2016;11: e0166281.

76 Damsgaard CT, Schack-Nielsen L, Michaelsen KF, et al: Fish oil affects blood pressure and the plasma lipid profile in healthy Danish infants. J Nutr 2006;136:94-99.

77 Stroobant W, Braun KV, Kiefte-de Jong JC, Moll HA, Jaddoe VW, Brouwer IA, et al: Intake of different types of fatty acids in infancy is not associated with growth, adiposity, or cardiometabolic health up to 6 years of age. J Nutr 2017;147:413-420

78 van Gijssel RM, Braun KV, Kiefte-de Jong JC, Jaddoe VW, Franco OH, Voortman T: Associations between dietary fiber intake in infancy and cardiometabolic health at school age: the Generation R study. Nutrients 2016;8:8. 